\title{
Predicting cognitive development and early symptoms of autism spectrum disorder in preterm children: The value of temperament and sensory processing
}

\begin{abstract}
This study was the first to longitudinally explore the extent to which early temperament and sensory processing were of predictive value for cognitive development and Autism Spectrum Disorder (ASD) symptomatology in a sample of preterm children $(N=50,22$ girls, mean gestational age 27 weeks). At the corrected ages of 10, 18, and 24 months, sensory processing and temperament were assessed, as were cognitive development and ASD symptoms at 36 months. Better cognitive development was predicted by fewer hospitalisation days at birth and by lower Activity Level at 18 months. Temperamental subscales of Negative Affect showed associations with both parent-reported and observational measures of ASD symptomatology, whereas sensory processing only had predictive value for parent-reported symptoms of ASD. The usefulness of temperament and sensory processing for prediction of ASD symptom severity and cognitive outcomes became clear in the second year of life. The results indicate that this area of research is worth additional investigation in the extreme and very preterm population, to explore in further detail whether these two concepts might be able to provide information about which preterms are more likely to develop ASD or cognitive impairments.
\end{abstract}




\section{Key words}

very preterm infants

autism spectrum disorder

temperament

sensory processing

cognitive development 


\section{Introduction}

Preterm infants (i.e. children born before 37 weeks of gestation) are at risk for a wide range of shortand long-term complications (Behrman \& Butler, 2007). For instance, several studies suggest that preterm birth affects the cognitive abilities of the child (e.g. Allotey et al., 2017), with mean cognitive test scores being significantly negatively associated with birth weight and gestational age (Bhutta, Cleves, Casey, Cradock, \& Anand, 2002). As such, preterm children born extremely early, before 28 weeks of gestation, and preterms born very early, between 28 and 32 weeks, are most at risk. Next to impaired cognitive capacities, preterm children also have an increased likelihood to develop Autism Spectrum Disorder (ASD). ASD is a neurodevelopmental disorder, which emerges in childhood and is characterised by difficulties in two main areas. First, people with ASD display persistent deficits in social communication and social interaction. Second, they exhibit restricted, repetitive patterns of behaviour, interests, or activities (Diagnostic and Statistical Manual of Mental Disorders, 5th ed; DSM5; American Psychiatric Association [APA], 2013). In the general European population, ASD has an estimated prevalence of $0.6 \%$ to $1.16 \%$ (Baird et al., 2006; Fombonne, 2009). Worldwide ASD prevalence is estimated to be $0.62 \%$ (Elsabbagh et al., 2012). In contrast, an ASD prevalence rate estimation of $7 \%$ was reported in a meta-analysis of 3366 preterm infants with a median gestation of 28 weeks (Agrawal, Rao, Bulsara, \& Patole, 2018). The ASD-likelihood seems to decrease with each additional week of gestational age (Kuzniewicz et al., 2014).

Studies show that a reliable ASD-diagnosis can be made from 2-3 years onwards (Charman \& Baird, 2002), although some research indicates that stability of diagnosis is already high as of 18 months or even somewhat earlier (Ozonoff et al., 2015; Pierce et al., 2019). However, at this age, a lot of children with ASD are not yet identified. The mean age of community diagnoses in Europe is about 40 months (Salomone, Charman, McConachie, \& Warreyn, 2015). As evidence suggests that interventions yield more improvement the younger the child is at the start of the intervention (Rogers et al., 2012), multiple studies have tried to find early markers that may be used for early identification of ASD. Recently, studies on this matter are mostly done in children with at least one older brother or sister with ASD. These siblings have up to $18.7 \%$ chance of developing ASD themselves (Ozonoff et al., 2011) and thus are - next to preterm children - another group at elevated likelihood (EL) for developing ASD. Up till now, no reliable markers of ASD have been consistently identified in children during their first year of life in the domain of social interaction (Zwaigenbaum et al., 2015), although 
this is the most obvious area of difficulties in ASD. Looking at other potential markers, there are some indications of motor abnormalities in the first year, e.g. concerning general movements (Einspieler et al., 2014) and head lag (Flanagan, Landa, Bhatt, \& Bauman, 2012). However, these problems are not very specific. It is therefore opportune to look for early markers of ASD in other domains. Temperament and sensory features might be good candidates, as they play an important role from birth on, and as group differences between children with ASD and typically developing children on these constructs have already been reported (e.g., Baranek, David, Poe, Stone, \& Watson, 2006; Macari, Koller, Campbell, \& Chawarska, 2017). Research furthermore indicates that both temperament and sensory features show associations with later ASD symptoms in EL-siblings (e.g., Garon et al., 2016; Baranek et al. 2018). An additional asset of temperament and sensory processing is that they have also been mentioned as predictors of cognitive functioning, mainly in studies with typically developing children (e.g. DiLalla et al., 1990). Thus, given the fact that preterm children are at elevated likelihood to develop both ASD and cognitive impairments, temperament and sensory features may be of particular interest in this population.

\subsection{Temperament}

The study of temperament has known a long history, with different approaches or 'traditions' (see Mervielde \& De Pauw, 2012). In the current study, temperament was assessed through instruments based on the psychobiological approach of Rothbart (1981). This approach defines temperament as individual differences in reactivity and self-regulation, with reactivity referring to the excitability and responsivity of a person to external and internal stimuli, and self-regulation referring to the modulation of this reactivity (Rothbart \& Derryberry, 1981). For each of the instruments based on this model, factor analysis consistently yielded three main factors of childhood temperament traits (Rothbart \& Bates, 2006). The first factor alludes to the extent to which a person tends towards high levels of positive affect. This factor is called Surgency, or Extraversion, and is often referred to as an approach system. People scoring high on Surgency show high activity levels, high-intensity pleasure seeking, impulsivity and low levels of shyness. The second factor is Negative Affect (NA) and refers to the overall susceptibility of the child to experience negative emotions. These first two factors combined encompass most aspects of the reactivity processes mentioned in the temperament definition. The last factor on the other hand, Effortful Control (EC), is tied to self-regulation processes. It covers one's capacity to regulate reactivity using attention. A second approach of temperament that is adopted in 
some of the studies described in the literature overview below, is the one by Thomas and Chess (1977). Research by Mervielde and Asendorpf (2000) showed parallels between the Thomas and Chess concept of Activity and Rothbart's Surgency factor, more specifically Activity Level and Positive Anticipation. Adaptability - the ability to modify reactions to stimuli in a desired way - overlaps with Rothbart's concept of 'Effortful Control', whereas the definition of the Persistence scale (also called 'Attention Span') is very similar to the definition of Rothbart's subscale 'Attentional Focusing'. Quality of Mood is tied to the NA factor of Rothbart. Threshold to Response refers to the amount of stimulation that is necessary to evoke responses in the child, and is as such a very similar concept to the subscale Perceptual Sensitivity of Rothbart. The dimensions of Intensity (the energy level of responses) and Rhythmicity (being unpredictable or irregular) are more difficult to link to a concept of Rothbart, but seem to fit in best under the factor of EC.

\subsubsection{Temperament and its association with $A S D$}

Literature points out that the temperamental profiles of preterm and full-term children differ. A number of studies delineate preterm children at the corrected ages of 3-9 months as significantly less adaptable than full-term children (Langkamp \& Pascoe, 2001). During this period they also seem to be more negative in mood and more intense (Langkamp \& Pascoe, 2001), more unpredictable or irregular (Gennaro, Tulman, \& Fawcett, 1990) and less persistent (Spungen \& Farran, 1986). This lowered persistence continues at 12 (Hughes, Shults, McGrath, \& Medoff-Cooper, 2002) and 24 months (Schraeder \& Medoff-Cooper, 1983). These findings seem to be contradicted by those of Sajaniemi, Salokorpi, and von Wendt (1998) who found preterms to be significantly less intense, less active, lower in threshold to respond, and more adaptive and positive in mood than controls at the age of 2 . As the link between temperamental features of preterm children and ASD has not yet been investigated, studies on this matter in other populations - such as EL-siblings and children with ASD could inform our hypotheses concerning the association between temperament and ASD in preterms. Garon and colleagues, for example, explored longitudinal connections between temperament and quantitative ASD symptoms in EL-siblings. At 24 months, both low levels of Behavioural Approach - a combination of the subscales Positive Anticipation, Attention Shifting and Activity Level - (Garon et al., 2009) and lower EC - including the scales Soothability, Low Intensity Pleasure, Inhibitory Control, Attention Shifting, Attention Focus, Activity Level and Anger - (Garon et al., 2016) were associated with more ASD symptoms at 36 months. Macari et al. (2017) furthermore found a link between 
Perceptual Sensitivity and autism severity in children with ASD. More specifically, higher autism severity at 43 months was associated with higher ADOS (Autism Diagnostic Observation Schedule, Lord et al., 2000) scores at 26 months and with lower change scores from 26 to 43 months for Perceptual Sensitivity.

\subsubsection{Temperament and cognitive development}

Studies in preterm children have shown cross-sectional relations between lower scores on cognitive tests and temperamental traits, such as less Persistence, less Approach, low Adaptability and low Activity Level (Ross,1987). Only a few studies conducted longitudinal research on temperament and cognitive development in preterms. Pérez-Pereira et al. (2016) reported that Approach, High and Low Intensity Pleasure, Sadness, Vocal Reactivity and Soothability as measured with the revised version of the Infant Behavior Questionnaire (IBQ-R; Gartstein \& Rothbart, 2003) at 10 months significantly contributed to language development at 30 months. Longitudinal research on this matter has also been conducted in the typically developing population. In both a study of DiLalla et al. (1990) and of Lemelin, Tarabulsy, and Provost (2006), Activity Level was related to IQ at 3 years. However, higher Activity Level was linked to higher IQ scores in the first study, but to lower IQ scores in the second one. Lastly, in the study of Slomkowski, Nelson, Dunn, and Plomin (1992), Affect-Extraversion (encompassing Interest in Persons, Cooperativeness, Fearfulness and Happiness) at age 2 contributed significantly to language scores at age 3. Similar longitudinal studies in EL-siblings or children with ASD have not yet been conducted.

\subsection{Sensory processing $(S P)$}

SP refers to the way in which incoming sensory stimuli of the seven sensory systems - the vestibular system, proprioception, vision, taste, hearing, touch and the olfactory sense - are managed by the central and peripheral nervous system (Miller \& Lane, 2000). The term SP does not only cover reception, modulation, integration, and organisation of the stimuli, it also encompasses the behavioural responses to the sensory input (Miller \& Lane, 2000). As of the latest version of the DSM5 (APA, 2013), hyper- or hyporeactivity for sensory stimuli, or unusual interest in sensory aspects have become part of the diagnostic criteria for ASD. In this study SP was operationalised by the Infant/Toddler Sensory Profile (ITSP; Dunn, 2002), based on the model of Winnie Dunn. This model assumes an interaction between neurological thresholds and behavioural responses. The neurological 
threshold indicates how much stimuli are needed for a child to perceive or react to the stimuli. The behavioural response concerns the way in which a child behaves towards its neurological threshold, passively or actively. The combination of these two concepts results in four quadrants: Sensation Seeking (high threshold, active response by arousing stimulation themselves), Low Registration (high threshold, passive response), Sensation Avoiding (low threshold, active response by trying to avoid the stimuli they perceive) and Sensation Sensitivity (low threshold, passive response). Besides quadrants, the ITSP gives additional information on five sections: auditory-, visual-, tactile-, vestibularand oral SP.

\subsection{1. $S P$ and its association with $A S D$}

Research indicates that preterm children show distinctive SP patterns in comparison to term-born children. A review of Bröring, Oostrom, Lafeber, Jansma, and Oosterlaan (2017) included six studies (Adams, Feldman, Huffman, \& Loe, 2015; Bart, Shayevits, Gabis, \& Morag, 2011; Crozier et al., 2016; Eeles et al., 2013a; Rahkonen et al., 2015; Wickremasinghe et al., 2013) which investigated their preterm sample with the ITSP. Except for the unambiguous presence of Low Registration, no clear pattern of problems emerged. However, none of these studies investigated the simultaneous presence of difficulties with SP and ASD symptoms. One study by Beranova and colleagues (2017) suggests an association between Sensation Seeking and ASD, as the screening accuracy of ASD in preterms increased significantly when combining the Sensation Seeking subscale with an ASD-screener. Again, evidence from other populations might inform our hypotheses concerning the preterm population, as quite some studies have investigated associations between SP and ASD symptoms in EL-siblings and children with autism. When looking at Restricted and Repetitive Behaviour (RRB), studies by Rogers, Hepburn, and Wehner (2003), Wiggins, Robins, Bakeman, and Adamson (2009), and Wolff et al. (2018) are unanimous that there is a significant relationship between SP and RRB. There is less consistency in the findings concerning the social-communicative deficits or Social Affect factor (SA) of ASD. Rogers et al. (2003) and Wiggins et al. (2009) found no correlation between ADOS_SA and the Short Sensory Profile (Dunn, 1999) in three-year-olds with ASD, whereas Watson et al. (2011) did find a correlation between SA and both Hyporesponsiveness and Sensation Seeking in four-year-olds with ASD. Also in the study of Baranek et al. (2018) elevated Sensation Seeking at 20-24 months was related to higher ADOS_SA in EL-siblings of 3-5 years. However, except for the study by Baranek et al. (2018), all of these studies looked at cross-sectional - instead of longitudinal - associations. 


\subsubsection{SP and cognitive development}

The few prospective studies that have been carried out on the association between SP and cognitive development in preterm children do not reach consensus. Rahkonen et al. (2015) found no association in preterms aged 24 months, whereas Chorna, Solomon, Slaughter, Stark, and Maitre (2014) reported an association between poor tactile responsivity at 12 months and worse motor and language scores at 24 months. The same disagreement can be observed in cross-sectional studies, with Case-Smith, Butcher, and Reed (1998), and Wickremasinghe et al. (2013) finding no relationship between the two concepts, while Buffone, Eickmann, and Lima (2016) concluded that the occurrence of cognitive delay was significantly higher in children with poor SP. Lastly, Eeles et al. (2013b) concluded that a stronger Low Registration and Sensation Avoiding pattern, and less frequent auditory, visual, touch, vestibular, and oral SP behaviours on the ITSP were related to delayed cognitive development at age 2. Factors that might be responsible for the discrepant results are the different measures of IQ and SP, and the different ages of the participants. Evidence from EL-siblings does not provide us with more clear conclusions, as to the best of our knowledge only one study exists on this topic (Wolff et al., 2018). In that study, no associations were found between the Mullen Scales

of Early Learning (MSEL; Mullen, 1995) at age 2 and the Sensory Experiences Questionnaire (SEQ; Baranek et al., 2006) in EL-siblings who later developed ASD. The abovementioned evidence on temperamental and sensory markers of ASD symptoms and cognitive development is summarised in the first five columns of Table 1. Only variables from studies providing longitudinal data in preschool children were adopted in this Table. Column five displays the effect sizes $\left(R^{2}\right)$ of the studies. As the $R^{2}$ always concerns models including more than only the temperamental or sensory processing variable that was adopted in Table 1 (e.g. IQ, sex, ..), additional $\beta$ - or t-values for each temperamental or sensory processing variable are reported.

\subsection{Conceptual overlap between temperament and sensory processing}

Evidence that temperament and sensory processing are related concepts is growing (Mammen et al., 2016). Dunn (2001) suggested that SP forms the basis of temperament. She formulated three hypotheses. First, she assumed that Low Registration enables task performance and thus could be related to EC. Second, she posed that Sensation Seeking is associated with Surgency. Lastly, she proposed that Sensation Avoiding and Sensation Sensitivity are linked to Fear and NA. These 
hypotheses were confirmed by a study of Nakagawa, Sukigara, Miyachi, and Nakai (2016) in typically developing children. Studies in children with ASD support some, but not all, of Dunn's hypotheses. In the study of Brock et al. (2012) for example, Sensory Seeking was not related to temperament. Chuang, Tseng, Lu, and Shieh (2012) however did find relations between Sensation Seeking and Surgency, between Low Registration and EC, but also between Low Registration and NA. As work by Green, Ben-Sasson, Soto, and Carter (2012) suggests that SP is related to anxiety in young children with ASD, it is possible that associations between SP and NA are not truly driven by temperament, but by emerging psychopathology.

\subsection{Current study}

In short, next to cross-sectional associations between temperament and SP on the one hand and cognitive development and ASD symptomatology on the other hand, evidence is emerging that temperament and SP might be of predictive value for cognitive development and ASD in children with ASD, EL-siblings, typically developing children, and preterm children. However, particularly in this last population, studies on this matter are scarce and demonstrate a lack of comprehensiveness. Studies moreover yield inconsistent findings due to variability in research designs, methods, and instruments, different techniques of analysis and differences in participant characteristics such as gestational age or age at the time of the study. The current study had three main goals. First, we were interested to explore the predictive value of early temperament and SP for social-communicative symptoms of ASD in a group of preterm children. We hypothesised that the scales of temperament and SP that emerged from studies with other populations (see Table 1, column 1-5) would also be the scales that predicted ASD symptoms and cognitive development in preterm children. However, as most of the findings in previous studies have not been obtained with the same instruments used in this study, to be able to formulate hypotheses, connections had to be made between the predictive scales of previous studies and the scales of the instruments used in this study (see column 6 of Table 1; the number after each instrument - e.g. IBQ-R_10, ITSP_18 or ECBQ_24 - refers to the age of the children at the time of the assessment, i.e. 10,18 or 24 months). A lot of the studies that are listed in Table 1 though, used some version of the Toddler Behavior Assessment Questionnaire (TBAQ, Goldsmith, 1996) to assess temperament, which was originally designed to follow up children who had previously been assessed with Rothbart's Infant Behaviour Questionnaire, and was further revised by Rothbart and colleagues. As such, there are some parallels between the TBAQ and the temperamental measures used in this 
study, making comparisons a bit easier. Concerning temperament and SP predicting parent-reported social-communicative symptoms of ASD, no previous studies on this matter have been performed. Our study was thus explorative on this part, but based on previous research indicating discrepancies between parental report and observational measures of ASD (e.g. Bishop \& Norbury, 2002; de Bildt et al., 2004), it was our hypothesis that different variables might predict observed versus parent-reported social-communicative symptoms. Our second goal was to explore the predictive value of early temperament and SP for the ASD-domain of RRB's. Here too, we expected that some of the variables in Table 1, under the header 'ADOS_RRB' would be the variables predicting observed RRB's, and that the variables predicting observed RRB's would not per se be the ones predicting parent-reported RRB's. Lastly, our third goal was to predict cognitive development at age 3 using early temperamental traits and SP. Again, our hypotheses were derived from previous studies on this topic in other populations. Since subscales of Surgency were particularly prominent for this outcome, it was our hypothesis that especially this temperamental factor would predict cognitive development. 
Table 1.

Summary of evidence on temperamental and sensory markers of ASD symptoms and cognitive development, including our hypotheses

\begin{tabular}{|c|c|c|c|c|c|}
\hline & Instrument & Population & Source & Effect Size $\mathbf{R}^{2}$ & Hypotheses \\
\hline \multicolumn{6}{|l|}{ ADOS_SA } \\
\hline Behavioral Approach (at 24 months) & TBAQ-revised & HR-siblings & Garon et al., 2009 & $0.44(\beta=-0.27)$ & $\begin{array}{l}\text { ECBQ_24 Activity Level (Surgency) + } \\
\text { ECBQ_24 Positive Anticipation (Surgency) } \\
+ \text { ECBQ_24 Attention Shifting (EC) }\end{array}$ \\
\hline Effortful Control (at 24 months) & TBAQ-revised & HR-siblings & Garon et al., 2016 & NR & $\begin{array}{l}\text { ECBQ_24 Effortful Control + ECBQ_24 } \\
\text { Soothability (NA) + ECBQ_24 Frustration } \\
\text { (NA) + ECBQ_24 Activity Level (Surgency) }\end{array}$ \\
\hline Perceptual Sensitivity (at 26-43 months) & TBAQ-supplemental & children with ASD & Macari et al., 2017 & $0.32(\beta=-0.15)^{a}$ & ECBQ_24 Perceptual Sensitivity (NA) \\
\hline Sensation Seeking (at 20-24 months) & SPA & HR-siblings & Baranek et al., 2018 & unstandardised $\mathrm{B}=0.071$ & ITSP_ 24 Sensation Seeking \\
\hline \multicolumn{6}{|l|}{ ADOS_RRB } \\
\hline Behavioral Approach (at 24 months) & TBAQ-revised & HR-siblings & Garon et al., 2009 & $0.45(\beta=-0.15)$ & $\begin{array}{l}\text { ECBQ_24 Activity Level (Surgency) + } \\
\text { ECBQ_24 Positive Anticipation (Surgency) } \\
+ \text { ECBQ_24 Attention Shifting (EC) }\end{array}$ \\
\hline Effortful Control (at 24 months) & TBAQ-revised & HR-siblings & Garon et al., 2016 & NR & $\begin{array}{l}\text { ECBQ_24 Effortful Control + ECBQ_24 } \\
\text { Soothability (NA) + ECBQ_24 Frustration } \\
\text { (NA) + ECBQ_24 Activity Level (Surgency) }\end{array}$ \\
\hline Perceptual Sensitivity (at 26-43 months) & TBAQ-supplemental & children with ASD & Macari et al., 2017 & $0.32(\beta=-0.15)^{a}$ & ECBQ_24 Perceptual Sensitivity (NA) \\
\hline \multicolumn{6}{|l|}{ PARENT-REPORTED MEASURES OF SA } \\
\hline \multicolumn{6}{|l|}{ No predictors found in literature } \\
\hline \multicolumn{6}{|l|}{ PARENT-REPORTED MEASURES OF RRB } \\
\hline \multicolumn{6}{|l|}{ No predictors found in literature } \\
\hline \multicolumn{6}{|l|}{ COGNITIVE DEVELOPMENT } \\
\hline Positive Anticipation (at 10 months) & IBQ-R & preterms & Pérez-Pereira et al., 2015 & $0.288(\beta=.249)^{b}$ & IBQ-R_10 Positive Anticipation (Surgency) \\
\hline High Intensity Pleasure (at 10 months) & IBQ-R & preterms & Pérez-Pereira et al., 2015 & $0.294(\beta=.279)^{c}$ & $\begin{array}{l}\text { IBQ-R_10 High Intensity Pleasure } \\
\text { (Surgency) }\end{array}$ \\
\hline Vocal Reactivity (at 10 months) & IBQ-R & preterms & Pérez-Pereira et al., 2015 & $0.294(\beta=.294)^{\mathrm{c}}$ & IBQ-R_10 Vocal Reactivity (Surgency) \\
\hline Low Intensity Pleasure (at 10 months) & IBQ-R & preterms & Pérez-Pereira et al., 2015 & $0.288(\beta=-.402)^{b}$ & IBQ-R_10 Low Intensity Pleasure (EC) \\
\hline Soothability (at 10 months) & IBQ-R & preterms & Pérez-Pereira et al., 2015 & $0.288(\beta=.180)^{b}$ & IBQ-R_10 Soothability (EC) \\
\hline Sadness (at 10 months) & IBQ-R & preterms & Pérez-Pereira et al., 2015 & $0.288(\beta=-.207)^{b}$ & IBQ-R_10 Sadness (NA) \\
\hline Activity Level (at 9 months) & IBR & TDP & DiLalla et al., 1990 & $0.32(\beta=.31)$ & IBQ-R_10 Activity Level (Surgency) \\
\hline Activity Level (at 15 and 18 months) & TBAQ & TDP & Lemelin et al., 2006 & $0.33(\beta=-.21)$ & ECBQ_18 Activity Level (Surgency) \\
\hline Affect-Extraversion (at 24 months) & IBR & TDP & Slomkowski et al., 1992 & $\begin{array}{l}\text { receptive language: } 0.18 ; t=2.30 \\
\text { expressive language: } 0.25 ; \mathrm{t}=2.02\end{array}$ & $\begin{array}{l}\text { ECBQ_24 Surgency + ECBQ_24 Fear } \\
\text { (NA) }\end{array}$ \\
\hline Poor response to tactile stimuli (at 12 months) & TSFI & preterms & Chorna et al., 2014 & NR & ITSP_10 Tactile Sensory Processing \\
\hline \multicolumn{6}{|c|}{ 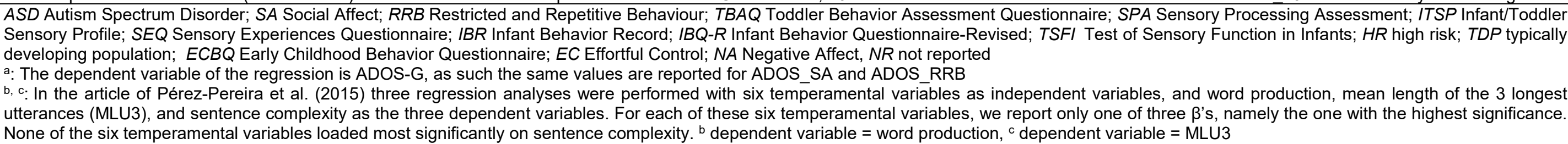 } \\
\hline
\end{tabular}




\section{Method}

\subsection{Participants}

Participants were recruited among all children born before 30 weeks of gestation in two Belgian hospitals between May 2012 and June 2013 (N=97). In Belgium, very preterm children are systematically followed up at fixed age points by specialised clinical centers. The children were recruited during their first visit at the center, approximately four months (corrected age) after discharge from the hospital. 23 out of the 97 families were not included in the final sample because they did not show up at the first visit $(n=6)$, because the pediatrician judged that the parents would not be able to participate in the study due to limited cognitive abilities $(n=2)$, because they did not master the Dutch language $(n=13)$ or because the child was under supervision of the juvenile court $(n=2)$. Seven of the remaining 74 families refused, resulting in a participation rate of $91 \%(n=67)$. These 67 children were then followed up throughout the first three years of their lives, at the corrected ages of $5,10,18$, and 24 months, and at the calendar age of 36 months. The data reported in this article were collected during the last four research moments, which took place at the University lab. After every visit the parents received a short written report and some questionnaires, which were to be filled in at home and sent back to the University.

Only participants with sufficient valid data were included for analysis. First, children who did not have any outcome data at 36 months, due to drop-out, were excluded $(n=12)$. Second, children who had missing data at 10, 18 ánd 24 months were removed $(n=5)$. This selection process resulted in a final sample of 50 children (Table 2). The children who were excluded for analyses were comparable to the included children on gender ratio $\left(t(65)=-1.477 ; p=.144 ; \eta_{p}^{2}=.032\right)$, gestational age $(t(65)=-0.542$; $\left.p=.590 ; \eta_{p}^{2}=.004\right)$, birth weight $\left(t(65)=-0.622 ; p=.536 ; \eta_{p}^{2}=.006\right)$, hospitalisation days $(t(55.144)=1.885$; $\left.p=.065 ; \eta_{p}^{2}=.019\right)$, and SES $\left(t(21.862)=1.194 ; p=.245 ; \eta_{p}^{2}=.029\right)$.

Table 2.

Sample characteristics of the included preterms $(n=50)$

\begin{tabular}{lll}
\hline & $n(\%)$ & \\
\hline Gender ratio (male/female) & $28 / 22(56 / 44)$ & \\
Number of twins & $24(48)$ & \\
BPD & $11(22)$ & \\
IRDS & $14(28)$ & range \\
IVH grade III/IV & $5(10)$ & $12-63.50$ \\
& $M(S D)$ & $605-1548$
\end{tabular}


Gestational age, weeks

Hospitalisaton days

Age mother at birth, years

Corrected age at time 1, months

Corrected age at time 2, months

Corrected age at time 3 , months

Age at time 4, months

$M$ mean; SD standard deviation; BPD Bronchopulmonary dysplasia; IRDS Infant Respiratory

Distress Syndrome; IVH Intraventricular Haemorrhage; SES Socioeconomic Status
24-29

$42-124$

23.04-46.08

9.73-12.00

18.00-19.60

23.40-25.50

35.33-41.07

\subsection{Measures}

\subsubsection{Sensory Processing}

The ITSP (Dunn, 2002; Dutch Translation by Rietman, 2007) is designed to assess sensory modulation abilities of children aged 0-36 months. Separate versions exist for children aged 0-6 months and 7-36 months. The last version is the one used in this study. It comprises 48 items, scored on a scale from 1 (almost always) to 5 (almost never). The items can be combined in four quadrant scores: Sensation Sensitivity, Sensation Avoiding, Sensation Seeking and Low Registration. Furthermore, five sections of sensory systems can be calculated, namely auditory-, visual-, tactile-, vestibular- and oral sensory processing. In this study, parents completed the ITSP when the children were 10, 18, and 24 months old (corrected age). The internal consistency of approximately half of the sections and quadrants of the ITSP exceeded 0.60 , the alpha threshold recommended by DeVellis (2016), with values between 0.63 (Auditory Sensory Processing at 24 months) and 0.76 (Auditory Sensory Processing at 18 months and Sensation Seeking at 24 months). The sections and quadrants of the ITSP with alpha's below 0.60 were excluded for analysis.

\subsubsection{Temperament}

The IBQ-R (Gartstein \& Rothbart, 2003; Dutch translation by Roest-de Zeeuw \& van Doesum) is a well-validated instrument based on the approach of Rothbart. This parent-reported instrument measures temperament of children aged 3-12 months and is comprised of 191 items, receiving a score from 1 (never) to 7 (always). In order to measure temperament longitudinally, a second questionnaire was needed to cover the age span of the children in our sample. The ECBQ (Putnam, Gartstein, \& Rothbart, 2006, Dutch translation by De Kruif et al.) is another well-validated temperament measure based on Rothbart's approach, for toddlers of 18-36 months. The instrument consists of 107 items, again scored on a 7-point Likert scale. Parents filled in the IBQ-R at the 
corrected age of 10 months and the ECBQ at the corrected ages of 18 and 24 months. The majority of the alpha's of the higher order scales of the IBQ-R and the ECBQ exceeded the 0.60 threshold (DeVellis, 2016), with values ranging from 0.64 (NA at 10 months) to 0.74 (EC at 18 months). Only the internal consistency of Surgency at 18 and 24 months was below the 0.60 threshold, and the same applied to NA at 24 months. These three higher order scales were not included in the regressions, but were instead substituted by their subscales. For this reason the internal consistency of the subscales making up for the higher order scales with alphas below 0.60 was also assessed. Except for four subscales (High Intensity Pleasure and Sociability at 18 months, and Activity Level and Motor Activation at 24 months), all subscales met the 0.60 threshold, with values ranging from 0.62 (Activity Level at 18 months) to 0.89 (Positive Anticipation at 18 months). The four subscales that did not reach the 0.60 threshold were excluded for analysis.

\subsubsection{Cognitive development}

At 36 months, cognitive development was assessed with the Mullen Scales of Early Learning (MSEL; Mullen, 1995). The MSEL measure cognitive competence and motor development of children aged 068 months. Adding up the subscales Visual Reception, Fine Motor and Receptive- and Expressive Language results in an Early Learning Composite ( $E L C, M=100, S D=15)$.

\subsubsection{ASD symptomatology}

The ADOS-2 (Lord et al., 2012) is a semi-structured, standardised assessment that is designed to elicit behaviour that is directly relevant to the diagnosis of ASD, on the domains of communication, social interaction, play, and restricted and repetitive behaviour. More ASD symptomatology is translated in higher scores. The ADOS-2 consists of five modules, to enable assessment of children and adults with differing developmental and language levels. In this study, either module $1(n=14)$ or module 2 ( $n=36)$ was used. The ADOS-2 administrations at 36 months were performed by ADOStrained psychologists and were all scored by the second author of this article, who achieved research reliability on the ADOS. We report scores for the subscales Social Affect (ADOS-2_SA) and Restricted and Repetitive Behaviours (ADOS-2_RRB). Calibrated Severity Scores (CSS; range 1-10) were used instead of raw scores, as these CSS are relatively independent of participant characteristics, such as age and verbal IQ, and therefore increase the comparability of scores on different ADOS-modules (Gotham, Pickles, \& Lord, 2009). 
We assessed parent-reported ASD-related behaviours at 36 months with the preschool version of the SRS-2 (Constantino \& Gruber, 2012; Dutch translation by Roeyers, Thys, Druart, De Schryver, \& Schittekatte, 2011). More ASD-related behaviours are reflected in a higher score on the SRS-2. The questionnaire comprises 65 items and falls apart in five subscales, that is, autistic mannerisms, social awareness, social cognition, social communication, and social motivation. Furthermore the SRS-2 provides two DSM-5 Compatible Subscales: Social Communication and Interaction (SRS-2_SCI) and Restricted and Repetitive Behaviour (SRS-2_RRB). In this study, raw scores of these last two scales are reported. The internal consistency of the SRS-2 proved to be sufficient in our sample, with alpha's of both the RRB scale (0.66) and the SCI scale (0.77) exceeding the 0.60 threshold (DeVellis, 2016).

\subsubsection{Socioeconomic Status}

We used the Hollingshead Index (Hollingshead, 1975) to assess SES of each participating family. This index provides a score, ranging from 8 to 66 , for each member of the family, based on their education (i.e. years of education and degree) and occupation. In two-parent families, SES was calculated as the mean of the scores of the two parents.

\subsection{Data analysis}

Five multiple linear regression analyses were performed to predict ADOS-2_SA, ADOS-2_RRB, SRS2_SCI, SRS-2_RRB, and MSEL at 36 months, using the measures of temperament and sensoryrelated features at 10,18 , and 24 months as dependent variables. In order not to overanalyse our data, for each outcome variable, we selected no more than four subscales of temperament and/or SP as predictors (Harrell, 2001). These subscales were chosen based on a combination of findings in previous studies (see Table 1) and Pearson's $r$ correlation coefficient analysis. Predictors from Table 1 were only included in our models if they showed a significant correlation with the outcome variable. If this was the case for more than four variables, the four with the highest Pearson's $r$ were selected. We only evaluated infant factors - such as gestational age, hospitalisation days and SES - in our models if significant correlations between these infant factors and the outcome measures were apparent. This was only the case for our MSEL model. For the two SRS-2 models, we also considered possible influences on reporting, such as education, age and gender of the reporting parent. No significant correlations between these factors and SRS-2 were noticed. As described in the introduction, there appears to be some conceptual overlap between the SP and temperamental variables examined in 
this study. Although only two of our regression models included both temperamental and sensory processing variables - and these were not the ones that were overlapping according to Dunn (see introduction, paragraph 1.3) - Variance Inflation Factors (VIF), indicating collinearity between the variables in our models, were closely considered. VIF values in all five regression models were however substantially beneath the threshold, so no variables were excluded based on this criterion. Our sample was furthermore characterised by almost $50 \%$ of twins. As parent ratings of a twin pair are not independent, we reanalysed the data while excluding one member of each twin pair, which did not change our results significantly. We also reran our five regression models with twin status as a predictor. Twin status was not significant in any of the models. As these two reanalyses of our data indicated that twin status did not alter our results significantly, and as our sample size is already limited, we decided to report the results of our sample while including all the twins and without including twin status as a predictor. In $84 \%$ of the cases in our sample, it was the mother who completed the parent-reported questionnaires at all four time points, whereas in $2 \%$ of the cases this was always the father. In the remaining $14 \%$ a combination of father- and mother report took place. Correlations between the parent-reported outcome measure (SRS-2) and the temperament and SP questionnaires at each time point were compared between the children for which the same parent filled out the questionnaires and the children for which this was not the case. The correlations were not systematically stronger when the SRS-2 and the temperament and SP questionnaires were filled out by the same person.

Although children without sufficient valid data were excluded from analyses (see paragraph 2.1), we still had some missing data, ranging from $2 \%$ on the SRS-2 to $22.4 \%$ on the ITSP at 24 months. Little's Missing Completely At Random Test (Little MCAR test; Little, 1988) confirmed that data were missing at random $\left(X^{2}(1194)=710.277, p=1.00\right)$. Expectation Maximization $(E M)$ was used to estimate these missing data.

The Statistical Package for the Social Sciences software version 25 (SPSS Inc., Chicago II, USA) was used to analyse the data. The overall significance level was set at 0.05 . As the approach for the SRS2 was exploratory, the predictors were entered in SPSS in a stepwise way. For the predictors of the other dependent variables, the 'enter' method was used. Assumptions of normality, linearity, homoscedasticity and absence of multicollinearity were met for all five regression analyses. 


\subsection{Ethics}

Approval of the local ethical committee was obtained and a written informed consent was signed by one of the parents of each child.

\section{Results}

\subsection{Preliminary analyses}

\subsubsection{Correlations between the outcome measures}

As in this study ASD symptoms were evaluated with an observational measure (ADOS-2) as well as with a parent-reported measure (SRS-2), Pearson's $r$ correlation coefficient analysis was performed to examine possible correlations between both measures. In case of high correlations, including only one of the two measures in our analysis could be sufficient. However, no significant correlations existed between scores on ADOS-2 and SRS-2 (Table 3). Scores on ADOS-2_SA were significantly correlated with scores on ADOS-2_RRB $(r=.341, p=.015)$. Analogous, a significant correlation was observed between SRS-2_SCI and SRS-2_RRB $(r=.523, p<.001)$. Scores on the MSEL were only significantly associated with scores on the SRS-2_RRB $(r=-.387, p=.006)$, not with ADOS-2.

Table 3.

Correlations between ADOS-2, MSEL and SRS-2 $(n=50)$

\begin{tabular}{lccccc}
\hline & ADOS-2_SA & ADOS-2_RRB & SRS-2_SCI & SRS-2_RRB & MSEL \\
\hline ADOS-2_SA & 1.00 & & & & \\
ADOS-2_RRB & $.341^{*}$ & 1.00 & & & \\
SRS-2_SCI & -.151 & .063 & 1.00 & & \\
SRS-2_RRB & .019 & .105 & $.523^{* *}$ & 1.00 & \\
MSEL & -.038 & .056 & -.250 & $-.387^{* *}$ & 1.00 \\
\hline
\end{tabular}

ADOS-2 Autism Diagnostic Observation Schedule-2; SRS-2 Social Responsiveness Scale-2; MSEL Mullen Scales of Early Learning; SA Social Affect; $S C /$ Social Communication and Interaction, RRB Restricted and Repetitive Behaviour ${ }^{*} p<.05 ;{ }^{* *} p<.01$

\subsubsection{Diagnostic and developmental outcome at 36 months}

The mean scores on ADOS-2, MSEL and SRS-2, reported in Table 4, suggest that our sample as a whole was not characterised by elevated ASD scores, or by delayed cognitive scores. However, there were some children scoring particularly low or high on these measures. Five children (10\%) scored below 70 on the MSEL, three children (6\%) scored 130 or higher. On the SRS-2, two children (4\%) showed a particular high level of social responsiveness, while 17 children (34\%) had mild shortcomings in their social responsiveness. One child (2\%) showed severe shortcomings on the 
SRS-2. Sixteen children (30\%) received ADOS total calibrated severity scores corresponding to an ADOS autism or ASD classification (Hus, Gotham, \& Lord; 2014) at 36 months. Eventually, six children received an ASD research diagnosis and an additional six children met the criteria of the BAP at 36 months (see Table 4). Concerning the ITSP, the means of all the subscales at 10, 18 and 24 months fell within the range of normal functioning. Across all three time points, on average $22.74 \%$ of our sample scored 'presumably' or 'definitely' higher than others (meaning hyperresponsivity on the five SP sections, and more Low Registration/Sensation Seeking/Sensory Sensitivity/Sensory Avoiding), whereas on average $7.29 \%$ scored 'presumably' or 'definitely' lower on these scales.

Table 4.

Diagnostic and developmental outcomes at 36 months $(n=50)$

\begin{tabular}{lll} 
& $M(S D)$ & range \\
\hline ADOS-2 total CSS & $2.74(1.82)$ & $1-9$ \\
SRS-2 total T score & $57.03(9.68)$ & $36-80$ \\
MSEL & $99.16(19.78)$ & $58-139.48$ \\
\hline & $n(\%)$ & \\
\hline diagnosis ASD / with developmental delay & $6(12) / 0(0)$ \\
BAP / with developmental delay & $4(8) / 2(4)$ \\
only developmental delay & $14(28)$ \\
none of the above & $24(48)$ & \\
\hline$M$ mean; SD standard deviation; ADOS-2 Autism Diagnostic Observation Schedule-2; CSS \\
Calibrated Severity Score; SRS-2 Social Responsiveness Scale-2; MSEL Mullen Scales of Early \\
Learning; ASD Autism Spectrum Disorder; BAP Broader Autism Phenotype
\end{tabular}

\subsection{Regression analyses}

\subsubsection{ADOS-2_SA}

A theoretical model containing one sensory and one temperamental subscale, namely ITSP_24 Sensation Seeking $(r=.322, p=.023)$ and ECBQ_24 Perceptual Sensitivity $(r=.393, p=.005)$ was put forward to predict ADOS-2_SA. The resulting model was significant $(F(2,47)=5.529, p=.007)$, with the independent variables accounting for $19 \%$ of the variance in ADOS-2_SA scores (Table 5). A significant $\beta$ was noted for the predictor ECBQ_24 Perceptual Sensitivity $(\beta=.317, t=2.244, p=.030)$.

Table 5.

Regression results for ADOS-2_SA ( $n=50)$

\begin{tabular}{lccccccc}
\hline & $\mathrm{B}$ & $\mathrm{SE} B$ & $\beta$ & $\mathrm{p}$ & $\mathrm{R}^{2}$ & $\mathrm{~F}(\mathrm{df})$ & $\mathrm{p}$ \\
\hline (constant) & -.827 & 1.173 & & &. $\mathbf{1 9 0}$ & $\mathbf{5 . 5 2 9}(\mathbf{2 , 4 7 )}$ & $\mathbf{. 0 0 7}$ \\
ITSP_24 Sensation Seeking & .043 & .030 & .205 & .153 & & & \\
ECBQ_24 Perceptual Sensitivity & .505 & .225 & .317 & .030 & & & \\
\hline
\end{tabular}

ADOS-2 Autism Diagnostic Observation Schedule-2; SA Social Affect; ITSP Infant/Toddler Sensory Profile; ECBQ Early Childhood Behavior Questionnaire

\subsection{2. $A D O S-2 \_R R B$}


Seven predictors emerged out of the literature as possible predictors of ADOS-2_RRB, of which only one - ECBQ_24 Perceptual Sensitivity $(r=.332, p=.018)$ - showed a significant correlation with this outcome measure in our sample. The overall model (Table 6$)$ was significant $(F(1,48)=5.965, p=.018)$, accounting for $11.1 \%$ of the variance in ADOS-2_RRB, with a significant $\beta$ for ECBQ_24 Perceptual Sensitivity $(\beta=.332, t=2.442, p=.018)$.

Table 6 .

Regression results for ADOS-2_RRB ( $n=50)$

\begin{tabular}{|c|c|c|c|c|c|c|c|}
\hline & B & SE B & $\beta$ & $\mathrm{p}$ & $\mathrm{R}^{2}$ & $F(d f)$ & $p$ \\
\hline (constant) & 1.784 & 1.435 & & & .111 & $5.965(1,48)$ & .018 \\
\hline ECBQ_24 Perceptual Sensitivity & .731 & .299 & .332 & .018 & & & \\
\hline
\end{tabular}

ADOS-2 Autism Diagnostic Observation Schedule-2; RRB Restricted and Repetitive Behaviour; $E C B Q$ Early Childhood Behavior Questionnaire

\subsection{3. $S R S-2$ SCl}

As no previous research focused on predicting SRS-2 outcome using temperament and sensory features, it was not possible to compose a model for SRS-2_SCl based on previous findings. Relying on Pearson's $r$ correlation analyses between SRS-2_SCI and all of the temperament and SP scales, the four scales with the highest correlations, i.e. ITSP_24 Low Registration $(r=-.530, p<.001)$, ECBQ_24 Effortful Control ( $r=-.539, p<.001)$, ECBQ_24 Positive Anticipation $(r=-.550, p<.001)$, and ECBQ_24 Soothability $(r=-.566, p<.001)$, were selected as predictors. Eventually, a significant model $(F(2,47)=15.035, p<.001)$ including ITSP_24 Low Registration $(\beta=-.316, t=-2.328, p=.024)$ and ECBQ_24 Soothability $(\beta=-.394, t=-2.900, p=.006)$ was obtained (Table 7). Together these two independent variables accounted for $39 \%$ of the variance in SRS-2_SCl scores.

Table 7.

Regression results for SRS-2_SCI $(n=50)$

\begin{tabular}{lccccccc}
\hline & $\mathrm{B}$ & $\mathrm{SE} \mathrm{B}$ & $\beta$ & $\mathrm{p}$ & $\mathrm{R}^{2}$ & $\mathrm{~F}(\mathrm{df})$ & $\mathrm{p}$ \\
\hline (constant) & 93.645 & 12.441 & & & $\mathbf{. 3 9 0}$ & $\mathbf{1 5 . 0 3 5 ( 2 , 4 7 )}$ & $\mathbf{. 0 0 0}$ \\
ITSP_24 Low Registration & -.705 & .303 & -.316 & .024 & & & \\
ECBQ_24 Soothability & -5.060 & 1.745 & -.394 & .006 & & & \\
\hline SRS_2 Son & $\mathrm{S}$ & & & & & \\
\end{tabular}

SRS-2 Social Responsiveness Scale-2; SCl Social Communication and Interaction; ITSP Infant/Toddler Sensory Profile; ECBQ Early Childhood Behavior Questionnaire

\subsubsection{SRS-2_RRB}

For this outcome measure, the four variables with the highest correlations were ITSP_18 Low Registration ( $r=-.446, p=.001)$, ITSP_18 Auditory Sensory Processing $(r=-.489, p<.001)$, ITSP_24 Low Registration ( $r=-.452, p=.001)$, and ECBQ_24 Soothability $(r=-.434, p=.002)$. Stepwise multiple 
regression analysis yielded a significant model $(F(2,47)=12.532, p<.001$, Table 8$)$, which was able to explain $34.8 \%$ of the variance in SRS-2_RRB. This model comprised ITSP_18 Auditory Sensory Processing $(\beta=-.394, t=-3.212, p=.002)$ and ITSP_24 Low Registration $(\beta=-.343, t=-2.797, p=.007)$.

Table 8.

Regression results for SRS-2 RRB $(n=50)$

\begin{tabular}{|c|c|c|c|c|c|c|c|}
\hline & $\mathrm{B}$ & SE B & $\beta$ & $p$ & $\mathrm{R}^{2}$ & $F(d f)$ & $p$ \\
\hline (constant) & 20.988 & 3.559 & & & .348 & $12.532(2,47)$ & .000 \\
\hline ITSP 18 Auditory Processing & -.218 & .068 & -.394 & .002 & & & \\
\hline ITSP_24 Low Registration & -.189 & .068 & -.343 & .007 & & & \\
\hline $\begin{array}{l}\text { SRS-2 Social Responsiveness } \\
\text { Infant/Toddler Sensory Profile }\end{array}$ & Scale-2; & $R R B$ & Restricte & and & Rep & Behaviour; & ITSP \\
\hline
\end{tabular}

\subsubsection{MSEL}

Eleven temperament and SP scales were retrieved from the literature as possible MSEL predictors. The two retained predictors after correlation analyses were ECBQ_18 Activity Level $(r=-.388, p=.005)$ and ECBQ_24 Sociability ( $r=-.367, p=.009)$. Furthermore, significant correlations between the MSEL and SES $(r=.337, p=.017)$, hospitalisation days $(r=-.373, p=.008)$ and gestational age $(r=.292, p=.039)$ were noticed. However, as gestational age and hospitalisation days were strongly correlated $(r=-.764$, $p<.000$ ), we did not correct for both hospitalisation days and gestational age in our model, but selected the one showing the strongest correlation with the MSEL, namely hospitalisation days. The regression analysis generated a significant model $(F(4,45)=5.233, p=.002)$, accounting for $31.7 \%$ of the variance (Table 9). A significant $\beta$ was observed for hospitalisation days $(\beta=-.265, t=-2.066, p=.045)$ and for ECBQ_18 Activity Level $(\beta=-.272, t=-2.120, p=.040)$.

Table 9

Regression results for the MSEL $(n=50)$

\begin{tabular}{lccccccc}
\hline & $\mathrm{B}$ & $\mathrm{SE} \mathrm{B}$ & $\beta$ & $\mathrm{p}$ & $\mathrm{R}^{2}$ & $\mathrm{~F}(\mathrm{df})$ & $\mathrm{p}$ \\
\hline (constant) & 157.592 & 26.692 & & & $\mathbf{3 1 7}$ & $\mathbf{5 . 2 3 3}(\mathbf{4 , 4 5 )}$ & $\mathbf{. 0 0 2}$ \\
hospitalisation days & -.237 & .115 & -.265 & .045 & & & \\
SES & .266 & .231 & .161 & .254 & & & \\
ECBQ_18 Activity Level & -6.830 & 3.222 & -.272 & .040 & & & \\
ECBQ_24 Sociability & -3.043 & 2.718 & -.160 & .269 & & & \\
\hline
\end{tabular}

MSEL Mullen Scales of Early Learning; SES Socioeconomic Status; ECBQ Early Childhood Behavior Questionnaire

\section{Discussion}

This study was the first to investigate temperament and SP longitudinally in relation to ASD symptoms and cognitive development in preterms. Regression analyses indicated that, as of the second year of 
life, both temperament and SP had some predictive value for later ASD symptom severity and cognitive development.

\subsection{Prediction of social-communicative symptoms of $A S D$}

More parent-reported social-communicative problems on the SRS-2 were predicted by a stronger pattern of Low Registration at 24 months. A possible explanation might be that children who register less of their environment, miss attempts to initiate social interaction from others, have fewer learning experiences, and develop less optimal social skills, as was also suggested by Jones, Gliga, Bedford, Charman, and Johnson (2014). Furthermore, considering temperamental predictors, less Soothability at 24 months showed a significant relationship with higher SRS-2_SCl scores. The relationship between Soothability - a scale belonging to the higher-order factor NA - and social-communicative problems may be quite straightforward. Children with low scores on the Soothability scale have difficulties with regulation, which might cause them to focus mainly on their own emotions instead of on social cues. As in the domain of temperament and SP no evidence was yet available on predictors of the SRS-2, we cannot compare our results with earlier findings. Concerning the observational measure of social-communicative ASD symptoms, no associations with SP were noticed. However, more Perceptual Sensitivity at 24 months - another subscale of NA - was a significant temperamental predictor of higher ADOS-2_SA. Previous research on temperamental predictors of ASD in children with ASD (Macari et al., 2017) also mentioned Perceptual Sensitivity. Children with a high score on this scale notice even very quiet sounds, sights, and small changes in the environment. This may distract them from social interactions, leading to more social-communicative problems.

\subsection{Prediction of RRB's in ASD}

More parent-reported RRB's at 36 months were predicted by more Auditory Sensory Processing at 18 months and by a stronger pattern of Low Registration at 24 months. Children might develop RRB's to cope with auditory stimuli, which they might perceive as invasive. Our finding of an association between RRB's and Low Registration, on the other hand, could mean that those children who close them off from the outside world at 24 months, are also the ones most occupied with their own world and their RRB's at 36 months. Alternatively, this association could be explained by RRB's being a form of self-stimulation at age 3 for those children who registered few stimuli at 24 months. SP did not have any predictive value for observational measures of RRB, as was also the case for the observational 
measures of social-communicative symptoms. Only Perceptual Sensitivity at 24 months was positively associated with ADOS-2_RRB, a subscale that previously already proved to be associated with autism severity in the research of Macari et al. (2017) in children with ASD. Children scoring high on Perceptual Sensitivity perceive a lot of stimuli from the environment, e.g. sights and sounds, which possibly causes them to develop RRB's in order to cope with these multiple stimuli. An alternative explanation is based on the fact that atypical sensory processing is - as mentioned in the introduction - part of the diagnostic criteria for ASD, and more specifically of RRB (DSM-5, APA, 2013). Infants with higher levels of RRB at age 3 may already show these patterns earlier in development, as suggested by our finding of higher Perceptual Sensitivity at age 2. This explanation is furthermore supported by the work of Ben-Sasson et al. (2009), who provided evidence of stability in sensory processing among both typically developing children and children with ASD.

\subsection{Prediction of cognitive development}

Our regression model revealed a longitudinal association between more hospitalisation days at birth and worse cognitive outcome at 36 months. As number of hospitalisation days was strongly associated with gestational age, we can conclude that severity of prematurity at birth is proportional to preschool cognitive scores. This finding is in line with that of Bhutta and colleagues (2002), who came to the same conclusion in school-aged preterms. Temperament proved to have some additional predictive value on top of the association with hospitalisation days, as lower Activity Level at 18 months was predictive for better cognitive outcome in our sample. This same association was found in the study of Lemelin et al. (2006) in typically developing children. It was suggested by Matheny (1989) that highly active children, as rated by their parents, may find it more difficult to attend to appropriate stimulation. No association between cognitive development and SP was observed in this study.

Summarizing, both observed social-communicative symptoms of ASD and observed RRB's were predicted by a temperamental subscale of NA, namely Perceptual Sensitivity. ADOS observations were not predicted by any SP scales. Low Registration was predictive for both social-communicative symptoms of ASD and RRB's, as reported by parents. Parent-reported RRB's were furthermore predicted by another SP scale, namely Auditory SP, while parent-reported social-communicative symptoms were predicted by a temperamental subscale of NA, namely Soothability. Lastly, cognitive development in preterm children was predicted by Activity Level, a temperamental subscale of 
Surgency, which was in line with our hypothesis. An overview of the main findings is provided in Table 10. Our hypothesis that different variables may predict parent-reported and observational measures of ASD was also confirmed, and the lack of correlations we found between these measures was in line with previous findings within this field of research (Bishop et al., 2002; de Bildt et al., 2004). However, not all of the subscales we hypothesised to be predictors turned out to actually be predictive. Several reasons might be accountable for this. For instance, some scales from Table 1 (e.g. Activity Level at 24 months) had to be excluded because they were not internally consistent. Temperament was furthermore not always assessed with instruments based on the Rothbart approach in previous studies. It could be that a concept that was measured by two different instruments does not cover exactly the same content and as such was predictive in a previous study but not in this study.

Table 10.

Summary of main findings

\begin{tabular}{lccccc}
\hline & ADOS_SA & SRS_SCI & ADOS_RRB & SRS_RRB & MSEL \\
\hline $\begin{array}{l}\text { Sensory Processing } \\
\text { Temperament }\end{array}$ & $\sqrt{ }$ & & & \\
$\quad$ NA & $\sqrt{ }$ & $\sqrt{ }$ & $\sqrt{ }$ & $\sqrt{ }$ \\
$\quad$ Surgency & & & & \\
$\quad$ EC & & & & \\
\hline
\end{tabular}

ADOS-2 Autism Diagnostic Observation Schedule-2; SRS-2 Social Responsiveness Scale-2; MSEL Mullen Scales of Early Learning; SA Social Affect; SCI Social Communication and Interaction, RRB Restricted and Repetitive Behaviour; NA Negative Affect; EC Effortful Control

\subsection{Limitations and future directions}

A first limitation of this study is the fact that temperament and SP were assessed solely by parent report, which is known to be subject to biases. Furthermore, the correlations that were found between the SRS-2 and the measures of temperament and SP are influenced by shared method variance, as both the SRS-2 and the temperamental and SP questionnaires are parent-reported assessments. However, the fact that parents are familiar with the behaviour of their child in different settings and over a longer period in time makes them a good source of information that should not be replaced, but rather be complemented by the use of multiple informants or observational measures. Second, our sample size was rather small. This, in combination with the fact that some of the temperamental and SP scales had to be excluded or had to be substituted by their subscales due to unsatisfactory internal consistency, prevented us to use all the scales of the temperament and SP questionnaires in our analyses. Moreover, a maximum of four predictors per outcome variable was selected (Harrell, 2001), which limited the conclusions that could be drawn from our analyses. Future research would benefit 
from larger samples. Third, given the limited internal consistency of some scales of the ITSP, IBQ-R and ECBQ in this study and given the fact that we cannot assume that instruments that are developed for typically developing children are as useful and valid in atypically developing children, it could be sensible to undertake research focused on the further validation of the ITSP, IBQ-R and ECBQ in children with an atypical development. Lastly, evidence that temperament and SP are related concepts is growing (e.g. Nakagawa et al., 2016). Given this suggested overlap, it could be interesting to perform a factor analysis with all of the items of the temperament and SP questionnaires. This could possibly result in new, more internally consistent scales that moreover might be more informative.

\subsection{Conclusion}

In this study, temperament at 18 months was predictive for cognitive development at 36 months, while temperament and SP at 18 and 24 months were associated with symptoms of ASD at 36 months. These findings extend similar previous research on the predictive value of temperament and SP in other populations. The results should however be nuanced, as a number of scales - especially the ones in the first year of life - that were predictive in research with other populations, turned out to have no significant predictive value in our study. Given that symptoms of ASD emerge in the second year of life, we have to be careful about considering markers at 18 and 24 months as predictive. When interpreting the results, we should furthermore keep in mind the abovementioned limitations of the study. Moreover, correlational group analyses are not sufficient in terms of prediction of outcome in individual cases. Nevertheless, our data provide a first indication that temperament traits and SP are worth further investigation in the extreme and very preterm population, in order to learn more about whether these two concepts might be able to provide information about which preterms are more likely to develop ASD or cognitive impairments.

\section{Acknowledgements}

We wish to thank all the children and their families for participating in this study. Furthermore, we want to express our gratitude to Ann Oostra, MD, Alexandra Casaer, MD, and their teams of the clinical follow-up centers for preterm born children, for their help during the recruitment of our participants. 
Adams, J. N., Feldman, H. M., Huffman, L. C., \& Loe, I. M. (2015). Sensory processing in preterm preschoolers and its association with executive function. Early Human Development, 91(3), 227-233. http://doi.org/10.1016/j.earlhumdev.2015.01.013

Agrawal, S., Rao, S. C., Bulsara, M. K., \& Patole, S. K. (2018). Prevalence of autism spectrum disorder in preterm infants: A meta-analysis. Pediatrics, 142(3), pii: e20180134. http://doi.org/10.1542/peds.2018-0134

Allotey, J., Zamora, J., Cheong-See, F., Kalidindi, M., Arroyo-Manzano, D., Asztalos, E., et al. (2017). Cognitive, motor, behavioural and academic performances of children born preterm: A metaanalysis and systematic review involving 64061 children. An International Journal of Obstetrics and Gynaecology, 125(1), 16-25. http://doi.org/10.1111/1471-0528.14832

American Psychiatric Association. (2013). Diagnostic and Statistical Manual of Mental Disorders, Fifth Edition. Arlington, VA: American Psychiatric Association.

Baird, G., Simonoff, E., Pickles, A., Chandler, S., Loucas, T., Meldrum, D., \& Charman, T. (2006). Prevalence of disorders of the autism spectrum in a population cohort of children in South Thames: The special needs and autism project (SNAP). The Lancet, 368, 210-215. https://doi.org/10.1016/S0140-6736(06)69041-7

Baranek, G. T., David, F. J., Poe, M. D., Stone, W. L., \& Watson, L. R. (2006). Sensory experiences questionnaire: Discriminating sensory features in young children with autism, developmental delays, and typical development. Journal of Child Psychology and Psychiatry, 47(6), 591-601. https://doi.org/10.1111/j.1469-7610.2005.01546.x

Baranek, G. T., Woynaroski, T. G., Nowell, S., Turner-Brown, L., DuBay, M., Crais, E. R., et al. (2018). Cascading effects of attention disengagement and sensory seeking on social symptoms in a community sample of infants at-risk for a future diagnosis of autism spectrum disorder. Developmental Cognitive Neuroscience, 29, 30-40. https://doi.org/10.1016/j.dcn.2017.08.006

Bart, O., Shayevits, S., Gabis, L. V., \& Morag, I. (2011). Prediction of participation and sensory modulation of late preterm infants at 12 months: A prospective study. Research in Developmental Disabilities, 32(6), 2732-2738. https://doi.org/10.1016/j.ridd.2011.05.037 
Behrman, R. E., \& Butler, A. S. (Eds.). (2007). Preterm birth: Causes, consequence, and prevention. Washington, DC: National Academy Press.

Ben-Sasson, A., Hen, L., Fluss, R., Cermak, S. A., Engel-Yeger, B., \& Gal, E. (2009). A meta-analysis of sensory modulation symptoms in individuals with autism spectrum disorders. Journal of Autism and Developmental Disorders, 39(1), 1-11. https://doi.org/10.1007/s10803-008-0593-3

Beranova, S., Stoklasa, J., Dudova, I., Markova, D., Kasparova, M., Zemankova, J., et al. (2017). A possible role of the Infant/Toddler Sensory Profile in screening for autism: A proof-of-concept study in the specific sample of prematurely born children with birth weights $<1.500 \mathrm{~g}$. Neuropsychiatric Disease and Treatment, 13, 191-200. https://doi.org/10.2147/NDT.S123066

Bhutta, A. T., Cleves, M. A. Casey, P. H., Cradock, M. M., \& Anand, K. J. S. (2002). Cognitive and behavioural outcomes of school-aged children who were born preterm: A meta-analysis. The Journal of the American Medical Association, 288(6), 728-37. https://doi.org/10.1001/jama.288.6.728

Bishop, D. V. M., \& Norbury, C. F. (2002). Exploring the borderlands of autistic disorder and specific language impairment: A study using standardised diagnostic instruments. Journal of Child Psychology and Psychiatry, 43(7), 917-929. https://doi.org/10.1111/1469-7610.00114

Brock, M. E., Freuler, A., Baranek, G. T., Watson, L. R., Poe, M. D., \& Sabatino, A. (2012). Temperament and sensory features of children with autism. Journal of Autism and Developmental Disorders, 42(12), 2271-2284. doi: 10.1007/s10803-012-1472-5

Bröring, T., Oostrom, K. J., Lafeber, H. N., Jansma, E. P., \& Oosterlaan, J. (2017). Sensory modulation in preterm children: Theoretical perspective and systematic review. Public Library of Science One, 12(2), e0170828. https://doi.org/10.1371/journal.pone.0170828

Buffone, F. R. R. C., Eickman, S. H., \& Lima, M. C. (2016). Sensory processing and cognitive development of preterm and full term infants. Brazilian Journal of Occupational Therapy, 24(4), 695-703. https://doi.org/10.4322/0104-4931.ctoAO0731

Case-Smith, J., Butcher, L., \& Reed, D. (1998). Parents' report of sensory responsiveness and temperament in preterm infants. American Journal of Occupational Therapy, 52(7), 547-555. https://doi.org/10.5014/ajot.52.7.547 
Charman, T., \& Baird, G. (2002). Practitioner Review: Diagnosis of autism spectrum disorder in 2- and 3-year-old children. Journal of Child Psychology and Psychiatry, 43, 289-305. https://doi.org/10.1111/1469-7610.00022

Chorna, O., Solomon, J. E., Slaughter, J. C., Stark, A. R., \& Maitre, N. L. (2014). Abnormal sensory reactivity in preterm infants during the first year correlates with adverse neurodevelopmental outcomes at 2 years of age. Archives of Disease in Childhood: Fetal \& Neonatal, 99(6), F475479. https://doi.org/10.1136/archdischild-2014-306486

Constantino, J. N., \& Gruber, C. P. (2012). Social Responsiveness Scale, second edition (SRS-2). Los Angeles, CA: Western Psychological Services.

Crozier, S. C., Goodson, J. Z., Mackay, M. L., Synnes, A. R., Grunau, R. E., Miller, S. P., et al. (2016). Sensory processing patterns in children born very preterm. American Journal of Occupational Therapy, 70(1), 7001220050p1-7. https://doi.org/10.5014/ajot.2016.018747

Chuang, I. C., Tseng, M. H., Lu, L., and Shieh J. Y. (2012). Sensory correlates of difficult temperament characteristics in preschool children with autism. Research in Autism Spectrum Disorders, 6(3), 988-995. https://doi.org/10.1016/j.rasd.2012.01.002

de Bildt, A., Sytema, S., Ketelaars, C., Kraijer, D., Mulder, E., Volkmar, F., et al. (2004). Interrelationship between Autism Diagnostic Observation Schedule-Generic (ADOS-G), Autism Diagnostic Interview-Revised (ADI-R), and the Diagnostic and Statistical Manual of Mental Disorders (DSM-VI-IV-TR) classification in children and adolescents with mental retardation. Journal of Autism and Developmental Disorders, 34(2), 129-137. https://doi.org/10.1023/B:JADD.0000022604.22374.5f

DeVellis, R. F. (2016). Scale development: Theory and applications (3rd ed.). Chapel Hill: University of North Carolina.

DiLalla, L. F., Thompson, L. A., Plomin, R., Phillips, K., Fagan, J. F. III, Haith, M. M., et al. (1990). Infant predictors of preschool and adult IQ: A study of infant twins and their parents. Developmental Psychology, 26(5), 759-769. https://doi.org/10.1037/00121649.26.5.759 
Dunn, W. (2002). Infant/Toddler Sensory Profile: User's Manual. San Antonio, TX: Psychological Corporation.

Dunn, W. (2001). The sensations of everyday life: Empirical, theoretical, and pragmatic considerations. American Journal of Occupational Therapy, 55(6), 608-620. https://doi.org/10.5014/ajot.55.6.608

Dunn, W. (1999). Development and validation of the short sensory profile. In W. Dunn (Ed.), The sensory profile examiner's manual. San Antonio, TX: The Psychological Corporation.

Eeles, A. L., Anderson, P. J., Brown, N. C., Lee, K. J., Boyd, R. N., Spittle, A. J., et al. (2013a). Sensory profiles of children born $<30$ weeks' gestation at 2 years of age and their environmental and biological predictors. Early Human Development, 89(9), 727-732. https://doi.org/10.1016/j.earlhumdev.2013.05.005

Eeles, A. L., Anderson, P. J., Brown, N. C., Lee, K. J., Boyd, R. N., Spittle, A. J., et al. (2013b). Sensory profiles obtained from parental reports correlate with independent assessments of development in very preterm children at 2 years of age. Early Human Development, 89(12), 1075-80. https://doi.org/10.1016/j.earlhumdev.2013.07.027

Einspieler, C., Sigafoos, J., Bölte, S., Bratl-Pokorny, K. D., Landa, R., \& Marschik, P. B. (2014). Highlighting the first 5 months of life: General movements in infants later diagnosed with autism spectrum disorder or Rett Syndrome. Research in Autism Spectrum Disorders, 8(3), 286-291. https://doi.org/10.1016/j.rasd.2013.12.013

Elsabbagh, M., Divan, G., Koh, Y-J., Kim, Y. S., Kauchali, S., Marcin, C., et al. (2012). Global prevalence of autism and other pervasive developmental disorders. Autism Research, 5(3), 160-179. https://doi.org/10.1002/aur.239

Flanagan, J. E., Landa, R., Bhat, A., \& Bauman, M. (2012). Head lag in infants at risk for autism: A preliminary study. American Journal of Occupational Therapy, 66, 577-585. https://doi.org/10.5014/ajot.2012.004192

Fombonne, E. (2009). Epidemiology of pervasive developmental disorders. Pediatric Research, 65(6), 591-598. https://doi.org/10.1203/PDR.0b013e31819e7203 
Garon, N., Bryson, S. E., Zwaigenbaum, L., Smith, I. M., Brian, J., Roberts, W., et al. (2009). Temperament and its relationship to autistic symptoms in a high-risk infant sib cohort. Journal of Abnormal Child Psychology, 37, 59-78. https://doi.org/10.1007/s10802-008-9258-0

Garon, N., Zwaigenbaum, L., Bryson, S., Smith, I. M., Brian, J., Roncadin, C., et al. (2016). Temperament and its association with autism symptoms in a high-risk population. Journal of Abnormal Child Psychology, 44(4), 757-769. https://doi.org/10.1007/s10802-015-0064-1

Gartstein, M. A, \& Rothbart, M. K. (2003). Studying infant temperament via the Revised Infant Behavior Questionnaire. Infant Behavior and Development, 26(1), 64-86. http://doi.org/10.1016/S0163-6383(02)00169-8

Gennaro, S., Tulman, L., \& Fawcett, J. (1990). Temperament in preterm and full-term infants at three and six months of age. Merrill-Palmer Quarterly, 35(2), 201-215.

Goldsmith, H. H. (1996). Studying temperament via construction of the Toddler Behavior Assessment Questionnaire. Child Development, 67(1), 218-235. https://doi.org/10.2307/1131697

Gotham, K., Pickles, A., \& Lord, C. (2009). Standardizing ADOS scores for a measure of severity in autism spectrum disorders. Journal of Autism and Developmental Disorders, 39(5), 693-705. https://doi.org/10.1007/s10803-008-0674-3

Green, S. A., Ben-Sasson, A., Soto T. W., \& Carter, A. S. (2012). Anxiety and sensory overresponsivity in toddlers with autism spectrum disorders: Bidirectional effects across time. Journal of Autism and Developmental Disorders, 42(6), 1112-1119. https://doi.org/10.1007/s10803-011-1361-3

Harrell, F. E. Jr. (2001). Regression modeling strategies: With applications to linear models, logistic regression and survival analysis. NY: Springer.

Hollingshead, A. A. (1975). Four-factor index of social status. Unpublished manuscript, Yale University, New Haven, CT.

Hughes, M. B., Shults, J., McGrath, J., \& Medoff-Cooper, B. (2002). Temperament characteristics of premature infants in the first year of life. Journal of Developmental and Behavioral Pediatrics, 23(6), 430-435. https://doi.org/10.1097/00004703-200212000-00006 
Hus, V., Gotham, K., \& Lord, C. (2014). Standardizing ADOS domain scores: Separating severity of social affect and restricted and repetitive behaviors. Journal of Autism and Developmental Disorders, 44(10), 2400-2412. https://doi.org/10.1007/s10803-012-1719-1

Jones, E. J. H., Gliga, T., Bedford, R., Charman, T., \& Johnson, M. H. (2014). Developmental pathways to autism: A review of prospective studies of infants at risk. Neuroscience and Biobehavioral Reviews, 39, 1-33. https://doi.org/10.1016/j.neubiorev.2013.12.001

Kuzniewicz, M. W., Wi, S., Qian, Y. G., Walsh, E. M., Armstrong, M. A., \& Croen, L. A. (2014). Prevalence and neonatal factors associated with autism spectrum disorders in preterm infants. Journal of Pediatrics, 164, 20-25. https://doi.org/10.1016/j.jpeds.2013.09.021

Langkamp, D. L., \& Pascoe, J. M. (2001). Temperament of pre-term infants at 9 months of age. Ambulatory Child Health, 7(3-4), 203-212. https://doi.org/10.1046/j.1467-0658.2001.00131.x

Lemelin, J., Tarabulsy, G. M., \& Provost, M. A. (2006). Predicting preschool cognitive development from infant temperament, maternal sensitivity, and psychosocial risk. Merrill-Palmer Quarterly, 52(4), 779-806. https://doi.org/10.1353/mpq.2006.0038

Little, R. J. A. (1988). A test of missing completely at random for multivariate data with missing values. Journal of the American Statistical Association, 83(404), 1198-1202. https://doi.org/10.2307/2290157

Lord, C., Risi, S., Lambrecht, L., Cook, E. H., Leventhal, B. L., DiLavore, P. C., et al. (2000). The Autism Diagnostic Observation Schedule-Generic: A standard measure of social and communication deficits associated with the spectrum of autism. Journal of Autism and Developmental Disorders, 30(3), 205-223. https://doi.org/10.1023/A:1005592401947

Lord, C., Rutter, M., DiLavore, P. C., Risi, S., Gotham, K., \& Bishop, S. (2012). Autism Diagnostic Observation Schedule, Second Edition (ADOS-2) Manual (Part I): Modules 1-4. Torrance, CA: Western Psychological Services.

Macari, S. L., Koller, J., Campbell, D. J., \& Chawarska, K. (2017). Temperamental markers in toddlers with ASD. Journal of Child Psychology and Psychiatry, 58(7), 819-828. https://doi.org/10.1111/jcpp.12710 
Mammen, M. A., Moore, G. A., Scaramella, L. V., Reiss, D., Shaw, D. S., Leve, L. D., et al. (2016). Infant patterns of reactivity to tactile stimulation during parent-child interaction. Infant Behavior and Development, 44, 121-132. https://doi.org/10.1016/j.infbeh.2016.06.004

Matheny, A. P., Jr. (1989). Temperament and cognition: Relations between temperament and mental test scores. In G. A. Kohnstamm, J. E. Bates, \& M. K. Rothbart (Eds.), Temperament in childhood (pp. 263-282). Oxford, England: John Wiley \& Sons.

Mervielde, I. \& Asendorpf, J. B. (2000). Variable-centered and person-centered approaches to childhood personality. In S. E. Hampson (Eds.), Advances in personality psychology (vol. 1, pp. 37-76). Philadelphia: Taylor \& Francis.

Mervielde, I., \& De Pauw, S. (2012). Models of child temperament. In M. Zentner \& R. Shiner (Eds.), Handbook of Temperament (pp. 21-40). New York: Guilford Press.

Miller, L. J., \& Lane, S. J. (2000). Toward a consensus in terminology in sensory integration theory and practice: Part 1. Taxonomy of neurophysiological processes. Sensory Integration Special Interest Section Quarterly, 23, 1-4.

Mullen, E. M. (1995). Mullen scales of early learning (AGS ed.). Circle Pines, MN: American Guidance Service Inc

Nakagawa, A., Sukigara, M., Miyachi, T., \& Nakai, A. (2016). Relations between temperament, sensory processing, and motor coordination in 3-year-old children. Frontiers in Psychology, 7, 623-629. https://doi.org/10.3389/fpsyg.2016.00623

Ozonoff, S., Young, G. S., Carter, A., Messinger, D., Yirmiya, N., Zwaigenbaum, L., et al. (2011). Recurrence risk for autism spectrum disorders: A baby siblings research consortium study. Pediatrics, 128(3), 488-495. https://doi.org/10.1542/peds.2010-2825

Ozonoff, S., Young, G. S., Landa, R.J., Brian, J., Bryson, S., Charman, T., et al. (2015). Diagnostic stability in young children at risk for autism spectrum disorder: A baby siblings research consortium study. Journal of Child Psychology and Psychiatry, 56, 988-998. https://doi.org/10.1111/jcpp.12421 
Pérez-Pereira, M., Fernández, P., Resches, M., \& Gómez-Taibo, M. L. (2016). Does temperament influence language development? Evidence from preterm and full-term children. Infant Behavior and Development, 42, 11-21. https://doi.org/10.1016/j.infbeh.2015.10.003

Pierce, K., Gazestani, V. H., Bacon, E., Barnes, C. C., Cha, D., Nalabolu, S., et al. (2019). Evaluation of the diagnostic stability of the early autism spectrum disorder phenotype in the general population starting at 12 months. JAMA Pediatrics, 173(6), 578-587. https://doi.org/10.1001/jamapediatrics.2019.0624

Putnam, S. P., Gartstein, M. A, \& Rothbart, M. K. (2006). Measurement of fine-grained aspects of toddler temperament: the Early Childhood Behavior Questionnaire. Infant Behavior \& Development, 29(3), 386-401. https://doi.org/10.1016/j.infbeh.2006.01.004

Rahkonen, P., Lano, A., Pesonen, A. K., Heinonen, K., Räikkönen, K., Vanhatalo, S., et al. (2015). Atypical sensory processing is common in extremely low gestational age children. Acta Paediatrica, 104(5), 522-528. https://doi.org/10.1111/apa.12911

Rogers, S. J., Estes, A., Lord, C., Vismara, L., Winter, J., Fitzpatrick, A. et al. (2012). Effects of a Brief Early Start Denver Model (ESDM)-based parent intervention on toddlers at risk for autism spectrum disorders: A randomized controlled trial. Journal of the American Academy of Child and Adolescent Psychiatry, 51(10), 1052-1065. https://doi.org/10.1016/j.jaac.2012.08.003

Rogers, S. J., Hepburn, S., \& Wehner, E. (2003). Parent reports of sensory symptoms in toddlers with autism and those with other developmental disorders. Journal of Autism and Developmental Disorders, 33(6), 631-642. https://doi.org/10.1023/B:JADD.0000006000.38991.a7

Ross, G. (1987). Temperament of preterm infants: Its relationship to perinatal factors and one-year outcome. Journal of Developmental and Behavioral Pediatrics, 8(2), 106-110. https://doi.org/10.1097/00004703-198704000-00007

Rothbart, M. K. (1981). Measurement of temperament in infancy. Child Development, 52(2), 569-578. https://doi.org/10.2307/1129176 
Rothbart, M. K., \& Bates, J. E. (2006). Temperament. In N. Eisenberg, W. Damon, R. M. Lerner (Eds.), Handbook of Child Psychology: Social, emotional, and personality development (pp. 99-166). New York: John Wiley \& Sons Inc.

Rothbart, M. K., \& Derryberry, D. (1981). Development of individual differences in temperament. In M. Lamb \& A. Brown (Eds.), Advances in developmental psychology (1st ed., pp. 37-86). Hillsdale, NJ: Erlbaum.

Sajaniemi, N., Salokorpi, T., \& von Wendt, L. (1998). Temperament profiles and their role in neurodevelopmental assessed preterm children at two years of age. European Child \& Adolescent Psychiatry, 7(3), 145-152. https://doi.org/10.1007/s007870050060

Salomone, E., Charman, T., McConachie, H., \& Warreyn, P. (2015). Child's verbal ability and gender are associated with age at diagnosis in a sample of young children with ASD in Europe. Child: Care, Health and Development, 42, 141-145. https://doi.org/10.1111/cch.12261

Schraeder, B., D., \& Medoff-Cooper B. (1983). Development and temperament in very low birth weight infants: The second year. Nursing Research, 32(6), 331-335. https://doi.org/10.1097/00006199-198311000-00003

Slomkowski, C. L., Nelson, K., Dunn, J., \& Plomin, R. (1992). Temperament and language: Relations from toddlerhood to middle childhood. Developmental Psychology, 28(6), 1090-1095. https://doi.org/10.1037/0012-1649.28.6.1090

Spungen, L. B., \& Farran, A. C. (1986). Effect of intensive care unit exposure on temperament in low birth weight preterm infants. Journal of Developmental and Behavioral Pediatrics, 7(5), 288292.

Thomas, A., \& Chess, S. (1977). Temperament and Development. New York: Brunner/Mazel.

Watson, L. R., Patten, E., Baranek, G. T., Poe, M., Boyd, B. A., Freuler, A. et al. (2011). Differential associations between sensory response patterns and language, social, and communication measures in children with autism or other developmental disabilities. Journal of Speech, Language, and Hearing Research, 54(6), 1562-1576. https://doi.org/10.1044/10924388(2011/10-0029) 
Wickremasinghe, A. C., Rogers, E. E., Johnson, B. C., Shen, A., Barkovich, A. J., \& Marco, E. J. (2013). Children born prematurely have atypical sensory profiles. Journal of Perinatology, 33(8), 631-635. https://doi.org/10.1038/jp.2013.12

Wiggins, L. D. , Robins, D. L., Bakeman, R., \& Adamson, L. B. (2009). Brief report: Sensory Abnormalities as distinguishing symptoms of autism spectrum disorders in young children. Journal of Autism and Developmental Disorders, 39(7), 1087-1091. https://doi.org/10.1007/s10803-009-0711-x

Wolff, J. J., Dimian, A. F., Botteron, K. N., Dager, S. R., Elison, J. T., Estes, A. M. et al. (2018). A longitudinal study of parent-reported sensory responsiveness in toddlers at-risk for autism. Journal of Child Psychology and Psychiatry. Journal of Child Psychology and Psychiatry, 60(3), 314-324. https://doi.org/10.1111/jcpp.12978

Zwaigenbaum, L., Bauman, M. L., Stone, W. L., Yirmiya, N., Estes, A., Hansen, R. L., et al. (2015). Early identification of autism spectrum disorder: Recommendations for practice and research. Pediatrics, 136, S10-40. https://doi.org/10.1542/peds.2014-3667C 